\title{
Evaluating the chlamydia and gonorrhoea screening program in the Humanitarian Entrant Health Service, Western Australia
}

\section{Veronica C Hoad MB BS, MPH, Public Health Registrar, Public Health and Ambulatory Care \\ Aesen Thambiran MB BS, FRACGP, Medical Director Humanitarian Entrant Health Service \\ North Metropolitan Area Health Service, Perth, WA. \\ Veronica.hoad@ health.wa.gov.au}

MJA 2012; 197: 47-49 doi: 10.5694/mjall.10745

\section{C}

hlamydia trachomatis and Neisseria gonorrhoeae are significant causes of sexually transmissible infections (STIs) worldwide, ${ }^{1}$ but there are limited data in the countries from which refugees originate to guide Australian screening of refugees for these diseases.

Before arrival, refugees being considered for Australian settlement undergo a limited health screen that includes screening for HIV and active tuberculosis (TB). Therefore, postarrival screening of refugees is essential to improve the health of the individual. The Humanitarian Entrant Health Service (HEHS) in Perth, Western Australia, aims to provide a free health assessment for refugees, including the recommended screening for infectious disease. ${ }^{2}$

The rationale for chlamydia and gonorrhoea screening is that failure to diagnose and treat patients with the diseases may result in transmission and significant complications, including pelvic inflammatory disease, ectopic pregnancy, infertility, conjunctivitis and pneumonia in newborn babies, ${ }^{3}$ and increased risk of HIV acquisition and transmission. ${ }^{4}$

The opportunistic screening guidelines for the general Australian population, as recommended by the Australasian Society for HIV Medicine (ASHM) ${ }^{5}$ compared with the separate Australian refugee screening guidelines recommended by the Australasian Society for Infectious Diseases (ASID), ${ }^{2}$ are outlined in Box 1 . From 2006 to 2009, the HEHS offered chlamydia and gonorrhoea screening consistent with the ASID guidelines.

The aim of this study was to document the prevalence of chlamydia and gonorrhoea in the refugee population settling in WA; to determine the individual and population health benefit of screening; and to make recommendations on the future screening of chlamydia and gonorrhoea in the refugee population.

\begin{abstract}
Abstrac:
Objectives: To document the prevalence of Chlamydia trachomatis and Neisseria gonorrhoeae in the refugee population settling in Western Australia from 1 January 2006 to 31 December 2009 and make recommendations for future screening for chlamydia and gonorrhoea in the refugee population.

Design and participants: A prevalence and quality assurance study of 2610 refugees aged 15 years and older who attended the Humanitarian Entrant Health Service in Western Australia and were screened for chlamydia and gonorrhoea.

Main outcome measures: Demographic details and results of $C$. trachomatis and $N$. gonorrhoeae tests on first void urine.

Results: The prevalence of chlamydia was found to be $0.8 \%(n=21)$ in the refugee population. No gonorrhoea infections were detected. The prevalence of chlamydia was low $(0.19 \%-1.23 \%)$ when analysed by sex, ethnicity or age and was considerably lower than other subpopulations considered high risk in Australia.

Conclusion: The low prevalence rates of chlamydia and gonorrhoea found in the refugee population suggest that current screening guidelines should be updated. We recommend screening all refugees who are sexually active up to age 39 years, taking into account an appropriate sexual history; otherwise, screening guidelines should be as for the general Australian population.
\end{abstract}

\section{Methods}

Demographic and clinical data for all refugees accepted by WA who presented for screening at the HEHS from 1 January 2006 to 31 December 2009 were entered into Medtech32 (Medtech Global, Auckland, New Zealand), a practice management software database used by the HEHS for all pathology test requests. All chlamydia and gonorrhoea tests were performed at PathWest Laboratory Medicine WA, Perth. Data for that period that we extracted from Medtech32 and entered into Microsoft Excel (Microsoft Corporation, Redmond, Wash, USA) included age and sex of refugees, country of origin and country of refuge, and requested polymerase chain reaction (PCR) tests for chlamydia and gonorrhoea.

The Western Australian Notifiable Infectious Diseases Database (WANIDD) is the WA statutory notification database that stores data on cases of chlamydia and gonorrhoea. Laboratory case data are transferred electronically to WANIDD, therefore it is a complete database of all laboratory cases of chlamydia and gonorrhoea diagnosed in the HEHS.
We extracted from WANIDD the chlamydia and gonorrhoea notifications for the period 1 January 2006 31 December 2009 to determine the number of chlamydia and gonorrhoea infections present in the HEHS population screened during that period.

We conducted a Cochran-Armitage trend test to examine if there was a significant trend of decreasing chlamydia prevalence with increasing age up to 39 years.

As a quality improvement study considered to be of negligible risk, our study was exempted from requiring ethics approval by the Sir Charles Gairdner Group Human Research Ethics Committee.

\section{Results}

Of an estimated 6222 refugees who settled in WA from 2006 to $2009^{6}$ and were eligible for screening, 4762 (76\%) responded to the invitation and underwent an HEHS assessment.

We restricted our study to participants aged 15 years and older, of whom there were 2812. Of this group, 2610 (93\%) had a documented chlamydia and gonorrhoea PCR test of first-void urine. About 55\% (1437/2610) were 
aged 15-29 years, and 20\% (529/2610) were 40 years or older. Fifty-six percent were African refugees, 33\% were South-East Asian and 8\% were Middle Eastern. Of the 202 participants who did not have a PCR test, 58\% were aged $15-17$ years and $12 \%$ were aged 50 years or older.

Box 2 shows the number screened by sex, ethnicity and age range, and $C$. trachomatis prevalence. No gonorrhoea infections were detected in the 2610 patients screened. The overall prevalence of chlamydia was found to be $0.8 \%(21 / 2610)$. The prevalence of chlamydia remained low (range, $0.19 \%-1.23 \%$ ) when analysed by sex, ethnicity and age. The CochranArmitage trend test did not show a significant trend of decreased chlamydia prevalence with increased age category from 20 to 39 years $(Z=0.7537$, $P=0.451)$.

\section{Discussion}

These prevalence data provide a valuable population-based estimate of chlamydia and gonorrhoea infection in the refugee population settling in WA, with the strength of a high percentage of the population having been screened. These prevalence estimates are surprisingly low, given that poverty, social instability,

\section{Summary of current Australian guidelines for screening for chlamydia and gonorrhoea in the general and refugee populations}

General population screening guidelines for sexually active adults, endorsed by the Australasian Society for HIV Medicine, ${ }^{5}$ recommend screening of:

- people aged 15-29 years

- people with a past history of sexually transmissible infections (STIs)

- men who have sex with men

- known contacts of a person with an STI

- people who have had sex overseas

- Indigenous clients

- people who don't use barrier forms of protection consistently with casual contacts

- people with multiple sexual partners

- people who have recently changed sexual partner

Australasian Society for Infectious Diseases refugee guidelines ${ }^{2}$ recommend that:

- all adult refugees, and others who are sexually active or may have been sexually assaulted, should be screened for Chlamydia trachomatis and Neisseria gonorrhoeae genital infection using a nucleic acid detection test on first-void urine mobility and lack of protection against sexual violence in the refugee population may facilitate STI transmission. ${ }^{2}$

The true prevalence of chlamydia infection in the Australian population is unknown. Recent estimates of women at low risk of infection include $3.4 \%$ for women aged 18-24 years attending general practices ${ }^{7}$ and $0.9 \%$ for women aged 18-35 years. ${ }^{8}$ The available data on disadvantaged populations and other subgroups (including people attending youth health centres, defence force staff, university attendees, backpackers, Indigenous people and prisoners) in Australia indicate a higher prevalence of chlamydia and gonorrhoea (between $5 \%$ and $20 \%$ ) than was found in the refugee population we studied. ${ }^{9-13}$ Based on these data, the refugee population may have a similar or lower prevalence of chlamydia compared with the general Australian population, and has a considerably lower prevalence than certain other highrisk subgroups.

Estimates of chlamydia and gonorrhoea prevalence in the countries of origin of the refugee intake are limited and vary considerably. ${ }^{14-19}$ While acknowledging the limited data available for comparison, the refugee population group settling in WA appear to have a low prevalence of chlamydia and gonorrhoea when compared with published data on prevalence in the population and high-risk groups in potential countries of origin.

There are several factors that may have had an impact on the prevalence of chlamydia and gonorrhoea in the refugee population settling in WA. Government screening of visa applicants for HIV $^{20}$ may exclude people at higher risk of STIs.

A recent new or casual sexual partner is a strong risk factor for having an STI. ${ }^{21}$ Culture, sex and migration pathway may influence sexual behaviours. Refugees who undergo processing off-shore, especially those who arrive in a family unit, may be unlikely to have had a recent new sexual partner during resettlement. This highlights the importance of taking an accurate, gender-appropriate and culturally appropriate sexual history in identifying refugees at risk of an STI who should subsequently be screened.

The proportion of refugees settling in different Australian states varies by ethnicity. During the study period, New South Wales had a higher proportion of refugees from Iraq compared with WA. ${ }^{22}$ Different refugee intakes by state could affect the generalisability of this study to refugee populations in other states.

\begin{tabular}{|c|c|c|c|c|}
\hline Characteristic & $\begin{array}{l}\text { No. of } \\
\text { refugees } \\
\text { screened }\end{array}$ & $\begin{array}{l}\text { No. tested } \\
\text { positive for } \\
\text { chlamydia }\end{array}$ & $\begin{array}{l}\text { No. tested } \\
\text { positive for } \\
\text { gonorrhoea }\end{array}$ & $\begin{array}{l}\text { Chlamydia } \\
\text { prevalence } \\
\left(95 \% \mathrm{Cl}^{*}\right)\end{array}$ \\
\hline \multicolumn{5}{|l|}{ Sex } \\
\hline Male & 1285 & 8 & 0 & $0.62 \%(0.27-1.23)$ \\
\hline Female & 1322 & 13 & 0 & $0.98 \%(0.52-1.68)$ \\
\hline \multicolumn{5}{|l|}{ Ethnicity } \\
\hline African & 1459 & 11 & 0 & $0.75 \%(0.38-1.35)$ \\
\hline South-East Asian & 874 & 9 & 0 & $1.03 \%$ (0.47-1.95) \\
\hline Middle Eastern & 216 & 1 & 0 & $0.46 \%(0.01-2.58)$ \\
\hline Other & 61 & 0 & 0 & $\mathrm{NI}$ \\
\hline \multicolumn{5}{|l|}{ Age range (years) } \\
\hline $15-19$ & 485 & 5 & 0 & $1.03 \%(0.33-2.41)$ \\
\hline $20-24$ & 487 & 6 & 0 & $1.23 \%(0.45-2.68)$ \\
\hline $25-29$ & 465 & 4 & 0 & $0.86 \%(0.23-2.20)$ \\
\hline $30-35$ & 361 & 3 & 0 & $0.83 \%(0.17-2.43)$ \\
\hline $35-39$ & 283 & 2 & 0 & $0.71 \%(0.08-2.55)$ \\
\hline$\geqslant 40$ & 529 & 1 & 0 & $0.19 \%(0.00-1.05)$ \\
\hline Overall & 2610 & 21 & 0 & $0.80 \%(0.50-1.23)$ \\
\hline
\end{tabular}

* Confidence intervals calculated using Byar approximation to the Poisson distribution. $\mathrm{NI}=$ not included as an individual estimate due to small numbers. 


\section{Conclusions and} recommendations

Chlamydia and gonorrhoea are not prevalent conditions in this cohort of refugees settling in WA. The low prevalence rates of chlamydia, especially in refugees aged over 40 years, suggest that the ASID guidelines recommending the screening of all adults should be updated.

If the ASHM guidelines on chlamydia and gonorrhoea screening were used as documented in Box 1, most chlamydial infections would be detected with less unnecessary testing. However, women aged 30-39 years are still at risk of complications from chlamydia, such as ectopic pregnancy and infertility. Prevalence estimates of chlamydia in refugees aged 30-39 years are not significantly lower than estimates for refugees aged 20 29 years. In addition, it is likely that their contact with the HEHS would be the first time many refugees would have been offered an STI screen. Therefore, in addition to the general Australian guidelines, we recommend considering routinely screening all refugees up to age 39 years.

Acknowledgements: We thank Donna Mak, Mitchell Smith and David Whyatt for their review of the original manuscript and Dr Jianguo Xiao for his help with data analysis.

Competing interests: No relevant disclosures.

Received 14 Jun 2011, accepted 20 Oct 2011

1 World Health Organization. Global prevalence and incidence of selected curable sexually transmitted infections: overview and estimates. Geneva:WHO, 2001. http://www.who.int/hiv/ pub/sti/who_hiv_aids_2001.02.pdf (accessed Feb 2012).

2 Murray R, Davis J, Krause V, et al; Australian Society for Infectious Diseases Writing Group. Diagnosis, management and prevention of infections in recently arrived refugees. Sydney: Dreamweaver Publishing, 2009. http:// www.asid.net.au/images/Documents/ Guidelines/RefugeeGuidelines.pdf (accessed Feb 2012)

3 Peipert JF. Clinical practice. Genital chlamydial infections. New Engl J Med 2003; 349: 2424-2430.

4 Fleming DT, Wasserheit JN. From epidemiological synergy to public health policy and practice: the contribution of other sexually transmitted diseases to sexual transmission of HIV infection. Sex Transm Infect 1999: 75: 3-17.

5 Sexual Health Society of Victoria. National management guidelines for sexually transmissible infections. Melbourne: SHSOV, 2008. http://mshc.org.au/Portals/6/ NMGFSTI.pdf (accessed Feb 2012).

6 Australian Government Department of Immigration and Citizenship. Settlers by calendar year of arrival by age on arrival [internet database]. Canberra: DIC, 2010. http:// www.immi.gov.au/living-in-australia/deliveringassistance/settlement-reporting-facility/ (accessed Jan 2010).

7 Walker J, Fairley CK, Bradshaw CS, et al. The difference in determinants of Chlamydia trachomatis and Mycoplasma genitalium in a sample of young Australian women. BMC Infect Dis 2011; 11: 35.

8 Hocking JS, Willis J, Tabrizi S, et al. A chlamydia prevalence survey of young women living in Melbourne, Victoria. Sex Health 2006; 3 : 235-240.

9 Kang M, Rochford A, Johnston V, et al. Prevalence of Chlamydia trachomatis infection among "high risk' young people in New South Wales. Sex Health 2006; 3: 253-254.

10 Buhrer-Skinner M, Muller R, Menon A, Gordon R. Novel approach to an effective communitybased chlamydia screening program within the routine operation of a primary healthcare service. Sex Health 2009; 6: 51-56.

11 Watkins RE, Mak DB, Connelly C. Testing for sexually transmitted infections and blood borne viruses on admission to Western Australian prisons. BMC Public Health 2009; 9: 385
12 Panaretto KS, Lee HM, Mitchell MR, et al. Prevalence of sexually transmitted infections in pregnant urban Aboriginal and Torres Strait Islander women in northern Australia. Aust NZ Obstet Gynaecol 2006; 46: 217-224.

13 McDonagh P, Ryder N, McNulty AM, Freedman E. Neisseria gonorrhoeae infection in urban Sydney women: prevalence and predictors. Sex Health 2009; 6: 241-244.

14 Clift S, Anemona A, Watson-Jones D, et al. Variations of HIV and STI prevalences within communities neighbouring new goldmines in Tanzania: importance for intervention design. Sex Transm Infect 2003; 79: 307-312.

15 Kamali A, Quigley M, Nakiyingi J, et al. Syndromic management of sexually-transmitted infections and behaviour change interventions on transmission of HIV-l in rural Uganda: community randomised trial. Lancet 2003; 361: 645-652.

16 Ghazal-Aswad S, Badrinath P, Osman N, et al. Prevalence of Chlamydia trachomatis infection among women in a Middle Eastern community. BMC Womens Health 2004: 4:3.

17 Siemer J, Theile O, Larbi Y, et al. Chlamydia trachomatis infection as a risk factor for infertility mong women in Ghana, West Africa. Am J Trop Med Hyg 2008; 78: 323-327.

18 Pépin J, Deslandes S, Khonde N, et al. Low prevalence of cervical infections in women with vaginal discharge in west Africa: implications for syndromic management. Sex Transm Infect 2004: 80: 230-235.

19 Okoror LE, Agbonlahor DE, Esumeh FI, Umolu PI. Prevalence of chlamydia in patients attending gynecological clinics in south eastern Nigeria. Afr Health Sci 2007; 7: 18-24.

20 Australian Government Department of Immigration and Citizenship. Health requirement for permanent entry to Australia. Form 107li. Canberra: DIAC, 2007. http://www.immi.gov.au/ allforms/pdf/107li.pdf (accessed Feb 2012)

21 Goulet V, de Barbeyrac B, Raherison S, et al; CSF group. Prevalence of Chlamydia trachomatis: results from the first national population-based survey in France. Sex Transm Infect 2010; 86 263-270.

22 Australian Government Department of Immigration and Citizenship. Population flows: immigration aspects. Canberra: DIC, 2008. http://www.immi.gov.au/media/publications/ statistics/popflows2006-7/title.pdf (accessed Feb 2012).

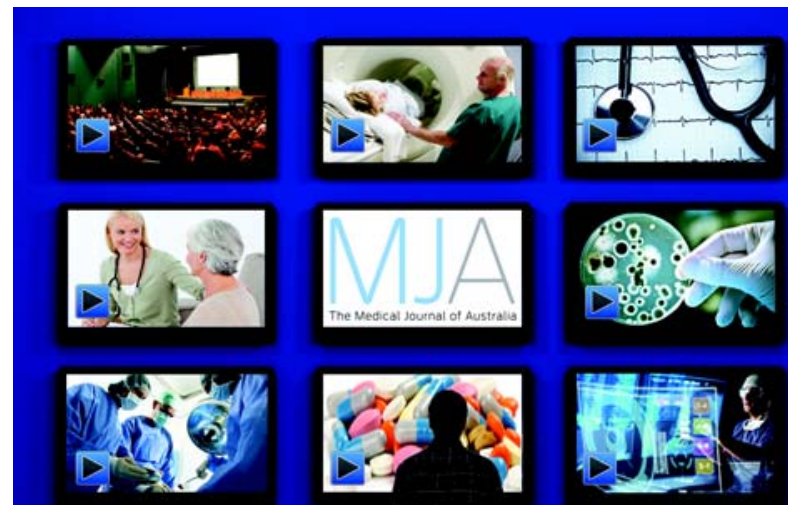

\section{MJA multimedia presentations}

The MJA invites authors to submit video and audio presentations relevant to the practice of clinical medicine in Australia for consideration for publication on the MJA website.

Multimedia presentations will be peer reviewed. Those considered to be of sufficient quality, academic rigour and relevance will be posted on the MJA website, with a brief summary being published in the MJA (citable in indexing services such as PubMed) linking to the presentation.

Video or audio presentations can be made specifically for the MJA or can be lectures, seminars or conference presentations (eg, clinical updates, demonstrations of clinical signs, or techniques). 